\title{
El plebérico corazón, Erasístrato y la plétora
}

\author{
Enrique Fernández Rivera \\ University of Manitoba
}

Uno de los pasajes de La Celestina al que más correcciones textuales se han propuesto son las palabras de Calisto en el primer acto, cuando, tras ordenar a Sempronio que enderece la cama y cierre la ventana de su aposento, exclama: "O bienaventurada muerte aquella que deseada a los afligidos viene $\mathrm{O}$ si viniessedes agora Eras y Crato medicos sentiriades mi mal $O$ piedad de silencio inspira en el pleberico coraçon porque sin esperança de salud no embie el espiritu perdido con el desastrado Piramo y de la desdichada Tisbe». Así es como el texto aparece en la edición de Burgos de 1499. ${ }^{1}$ Sería muy largo intentar resumir aquí las muchas interpretaciones y correcciones que se han propuesto a este pasaje, en el que ya la edición de Salamanca de 1570 cambió los nombres de los médicos Eras y Crato por el del conocido médico alejandrino Erasístrato. Baste decir que hoy muchos críticos aceptan esta corrección, junto con la de «piedad de Seleuco» por "piedad de silencio». ${ }^{2}$ Con estas dos correcciones, las palabras de Calisto se convierten en una clara referencia a la anécdota del famoso diagnóstico por las palpitaciones de corazón que Erasístrato hiciera de la misteriosa enfermedad que tenía postrado al borde de la muerte a Antíoco, el hijo del rey Seleuco, que estaba secretamente enamorado de su madrastra Estratonice. Mi intención en este artículo es proponer otra enmienda textual a este pasaje. Mi propuesta es que, en el original perdi-

1.- Fernando de Rojas, La Celestina: Two Facsimiles (1499? and 1528), New York, Hispanic Society of America, 1995, p. 2v.

2.- Para evitar una larguísima nota sobre la historia de estas dos correcciones textuales, me remito a dos excelentes resúmenes: Marcelino V. Amasuno, Sobre la aegritudo amoris y otras cuestiones fisiátricas en La Celestina, Madrid, CSIC, 2005, pp. 114-15, n. 22; Ricardo Castells, «El mal de amores de Calisto y el diagnóstico de Eras y Crato, médicos», Hispania, 76.1 (1993), pp. 55-56. 
do del Antiguo Autor, la problemática expresión «plebérico corazón» era "pletórico corazón». Esta nueva enmienda concuerda con las dos anteriormente señaladas ya que la plétora es un diagnóstico médico asociado precisamente con Erasístrato. Como veremos, con esta enmienda el pasaje se unifica en torno a la figura de Erasístrato, de cuya reputación médica Calisto se burla para mostrar la gravedad del mal de amor que le aflige.

Por la dificultad de encontrarle un sentido claro en el estropeado pasaje en que está situado, el significado de "plebérico corazón» ha venido causando problemas desde antiguo. La interpretación más extendida es la que ya hizo el anónimo autor de Celestina comentada a finales del XVI en una de las glosas: "'En el pleberico coraçon': Id est en el coraçon de Pleberio padre de Melibea, e puedelo dessear para que le diesse a su hija Melibea». ${ }^{3}$ La otra interpretación, que aparece por primera vez en la edición de Cejador, considera que el adjetivo "plebérico» es usado como un gentilicio y que se refiere al corazón de Melibea, hija de Pleberio. ${ }^{4}$ Sin embargo, tanto una como otra interpretación dejan el sentido del pasaje un tanto en el aire. Si el plebérico corazón se refiere al corazón de Pleberio, no se entiende qué tiene que ver la piedad de Seleuco de renunciar a su esposa con la situación que se plantea en La Celestina, a menos que, en la versión perdida del Antiguo Autor, Melibea fuera una joven casada con un viejo llamado Pleberio, como Miguel Marciales propuso. ${ }^{5} \mathrm{Si}$ el plebérico corazón se refiere al de Melibea, ¿a qué viene mencionar la piedad paternal de Seleuco en una situación en la que el único problema a resolver es el desdén que Melibea siente por Calisto? Otro grave problema con la expresión "plebérico corazón" ha sido señalado por Ruiz Ramón: el personaje de Pleberio no aparece nunca citado en el esbozo del Antiguo Autor que le llegó a Rojas. Por tanto, o Rojas era el autor de toda la obra, o bien Pleberio fue un nombre y personaje que Rojas se vio obligado a crear a posteriori a partir del adjetivo "plebérico». ${ }^{6}$ Igualmente problemática es la rareza tanto del adjetivo "plebérico» como del nombre "Pleberio", ambos verdaderos hápax antes de Rojas. Si bien existen variantes del nombre Plebeius en la literatura anterior, no hay ningún caso registrado de "Pleberio», un nombre que, además, parece encajar mal con

3.- Celestina comentada, ed. Louise Fothergill-Payne, Enrique Fernández Rivera y Peter Fothergill-Payne, Salamanca, Ediciones Universidad de Salamanca, 2002, p. 11.

4.- J. Cejador y Frauca, ed., La Celestina, 2 vols., Madrid, Espasa Calpe, 1913, vol. I, p. 36. Sería otra vez una nota muy larga intentar resumir, o meramente citar, todas las contribuciones a este debate de a quién se refiere el "plebérico corazón». Véase un excelente resumen en Donald McGrady, "Two Studies on the Text of the Celestina», Romance Philology, 48.1 (1994), pp. $1-21$.

5.- Miguel Marciales, ed., Celestina: Tragicomedia de Calisto y Melibea, Illinois Medieval Monographs, edición al cuidado de Brian Dutton y Joseph T. Snow, 2 vols., Urbana, University of Illinois Press, 1985, vol. 1, p. 85.

6.- Francisco Ruiz Ramón, "Nota sobre la autoría del Acto I de La Celestina», Hispanic Review, 42 (1974), pp. 431-35. 
la nobleza que se atribuye a la familia de Melibea. Igualmente, el adjetivo derivado del nombre Pleberio más esperable hubiera sido "pleberiano", no "plebérico»?

A diferencia del sospechoso y no atestiguado adjetivo "plebérico", el adjetivo "plet(h)órico» está bien testimoniado en la época, tanto en latín como en castellano. En el siglo XV plétora era un tecnicismo de la medicina humoral para referirse a un exceso de humores - especialmente del principal de los humores, la sangre. ${ }^{8}$ Un ejemplo del uso del adjetivo "pletórico» en este sentido es la primera edición en castellano del popular Lilio de medicina de Bernardo de Gordón (1495). En más de veinte ocasiones este texto habla de "cuerpos pletóricos», para los que recomienda la sangría, una terapia que, como veremos, está implícita en las palabras de Calisto. ${ }^{9}$ Igualmente, las formas plethoricus y plethora son frecuentes en el corpus galénico y otros textos médicos en latín al uso en la época. Aunque la expresión "corazón pletórico» no aparece literalmente en estos textos, la plétora es presentada como una afección que puede afectar prácticamente a todos los órganos del cuerpo, incluido el corazón, caso que es calificado como mortal de necesidad. Fuera de este uso técnico en los textos de medicina, el adjetivo "pletórico" y las referencias a la plétora no son frecuentes en otros textos de la época. Esta situación es curiosamente la inversa del castellano moderno. Hoy la palabra "plétora» y sus derivados han desaparecido del vocabulario médico pero son frecuentes en el lenguaje común, donde la palabra ha perdido todo valor técnico y tiene sólo un sentido de abundancia, como es el caso en clichés del tipo "pletórico de fuerzas» o "plétora de oportunidades». ${ }^{10}$

7.- Marciales, Celestina: Tragicomedia de Calisto y Melibea, vol. I, p. 86. Hasta qué punto estaban los lectores y autores familiarizados con los nombres de la antigüedad clásica se puede ver en una nota que Kaspar Barth, el traductor al neolatín de La Celestina, hace al nombre de Sempronio, que asocia con Sempronio Graco: «Aunque el autor [de La Celestina] trató otros aspectos de su obra de manera conveniente, me sorprende mucho que haya llamado a un vil sirviente 'Sempronio', una decisión a la que los hermanos Graco se hubieran opuesto» ("Et caetera quidem satis concinne auctor noster adscivit, Sempronium autem vilissimo servulo dedisse equidem miror, cui rei intercesserint Gracchi»), en Kaspar von Barth, Pornoboscodidascalus Latinus (1624): Kaspar Barth's Neo-Latin Translation of Celestina, ed. Enrique Fernández, Chapel Hill, North Carolina Studies in the Romance Languages and Literatures, 2006, p. 172, traducción al español mía.

8.- La palabra plétora ha caído completamente en desuso en medicina a partir de principios del siglo xx, cuando aún se la puede encontrar en algunos títulos médicos en español, curiosamente asociada al corazón, como en Agustín del Cañizo y García, Las cardiopatías de la plétora, Madrid, Sucesor de Enrique de Teodoro, 1917, quien también habla de «hipertensión por plétora» y de "plétora abdominal» (pp. 25 y 28).

9.- Sobre la posible influencia del Lilio de medicina en La Celestina véase Dennis Seniff, «Bernardo Gordonio's Lilio de medicina: A Possible Source of Celestina», Celestinesca, 10.1 (1986), pp. 13-18, y Bienvenido Morros Mestres, "La Celestina como Remedium Amoris», Hispanic Review, 72 (2004), pp. 77-99.

10.- El índice del tomo xx de la edición del corpus galénico de Kühn contiene largas entradas para plethora y plethoricus que muestran su extendido uso en este autor (Galeno, Claudii 
Esta rareza en la época del adjetivo "pletórico» en textos que no fueran médicos, ayudada probablemente por el hecho de que el revelador nombre de Erasístrato tampoco se leyera en el manuscrito del que leían, hicieron que Rojas o un copista anterior malentendiera la expresión «pletórico corazón» y la transcribiera como «plebérico corazón». Un error de copia de este tipo es fácilmente explicable desde un punto de vista paleográfico dado que la palabra "plet(h)orico» - sea escrita con cualquiera de las dos grafías atestiguadas, es decir, con "th» o sólo con "t»— se presta a ser leída erróneamente como "pleberico". Si la forma que aparecía en el texto del Antiguo Autor era la más frecuente - es decir, la forma con «th», "plethórico»- el error de lectura sería aun más fácil dado que en la época la «th» es a menudo abreviada en un solo rasgo ascendente común a las dos letras. Confusiones semejantes en que los rasgos ascendentes de una letra se leen como parte de otra letra que la sigue o la precede abundan en la transmisión textual de La Celestina durante los siglos XVI y XVII. Así es el caso con muchos nombres propios y adjetivos gentilicios, como «Pericles», cuyas letras "cl» se transcribieron como «d», dando la forma «Perides» en la edición de Zaragoza, 1507. Un cambio en el sentido contrario es el caso de la referencia a la bruja Adelecta en el sexto acto, en que la secuencia "de» se copió como "th» en muchas ediciones antiguas, que presentan la lectura "Athleta». ${ }^{11}$ Por último, la influencia del vocablo latino "plebs" y sus muchos derivados explica la transformación del incomprensible "pleborico", la forma inicialmente resultante de esta mala lectura, en la forma "pleberico", también extraña pero con más apariencia de credibilidad.

Para comprender las implicaciones que la expresión original «plet(h) órico corazón» añade a las palabras de Calisto en el texto original hay que entender el importante papel de la plétora en la medicina humoral predominante en la época. Plethora es la transcripción latina del griego $\pi \lambda \eta \theta \omega ́ \rho \alpha$, cuya traducción latina es plenitudo, forma que convive con la forma transcrita indiscriminadamente en los textos médicos. La plétora era un diagnóstico relacionado con procesos de inflamación y fiebre, como flemones y apostemas, y estaba fuertemente asociada con la figura de Erasístrato. Según cuenta Galeno, el médico del periodo helenístico Erasístrato consideraba como la etiología de casi todas las enfermedades una

Galeni opera omnia, medicorum Graecorum opera quae extant, ed. Karl Gottlob Kühn, 20 vols., Hildesheim, Olms, Reprographischer Nachdruck der Ausg. Leipzig, 1821-33, 1964, vol. 20, pp. 487-88). Existen también en español variantes como "plectora» y "plectorico», así como "pletura», tanto en la grafía con «th» como en la grafía con «t». Para otros casos atestiguados del uso de esta palabra en castellano en el siglo xv, véase María Teresa Herrera, Diccionario español de textos médicos antiguos, 2 vols., Madrid, Arco Libros, 1996, vol. 2., p. 1234, donde se citan varios ejemplos.

11.- Patrizia Botta, "Onomástica y crítica textual: peripecias de los nombres propios en $L a$ Celestina», Criticón, 87-88-89 (2003), pp. 97-111. 
abundancia excesiva de sangre, lo que denominaba plétora. Un proceso de hinchazón y fiebre por el exceso de sangre en un órgano desplazaba el pneuma o elemento vital de los órganos afectados. El adjetivo "pletórico" para Erasístrato era pues sinónimo de enfermo por exceso de sangre, inflamación dolorosa y fiebre, un proceso que podía afectar a todos los órganos internos o externos, incluido el corazón. ${ }^{12}$

El «plet(h)órico corazón» del texto del Antiguo Autor se refería pues al corazón de Calisto, quien en este pasaje se presenta como enfermo de amor utilizando tanto la anécdota de la cura de Antíoco como el diagnóstico de la plétora, ambos temas relacionados con la figura de Erasístrato. Al llamar a su corazón pletórico, Calisto está refiriéndose a una parte de los bien conocidos efectos físicos de la aegritudo amoris en el corazón que coincide con los de la plétora, como son la inflamación, la arritmia y la fiebre o sudores. ${ }^{13}$ Que el corazón aludido en este pasaje no sea el de Pleberio o Melibea, sino el del enamorado Calisto encaja con el sentido general de un pasaje en el que éste está claramente quejándose de su mal de amor. ¿Qué otro órgano más apropiado que su corazón para localizar este dolor del que está hablando? Igualmente encaja con que el corazón aludido sea el de Calisto enamorado la alusión en el pasaje al caso del también enamorado hijo de Seleuco, cuyos famosos síntomas que permitieron a Erasístrato diagnosticar el mal eran precisamente las palpitaciones de corazón. ${ }^{14}$ Finalmente, esta atribución del corazón a Calisto está implícita en la respuesta de Sempronio. Al principio, Sempronio no comprende las palabras de su amo, como denota su réplica inicial: «¿Qué cosa es?». Algo más adelante, sin embargo, las comprende y dice para sí: «dejemos

12.- Galeno, ed. Kühn, vol. XI, p 155; vol. iII, p. 492. Para una visión del concepto de la plétora en la medicina de la antigüedad, véase R. Fuchs, "Die Plethora bei Erasistratos», Neue Jahrbüche für Philologie und Pädagogie, 38 (1892), pp. 679-91. Una completa descripción de la plétora y su papel en la etiología de la enfermedad como inflamación por exceso de sangre que se resiste al pneuma bombeado desde el ventrículo izquierdo del corazón es Charles R. S. Harris, The Heart and the Vascular System in Ancient Greek Medicine from Alcmaeon to Galen, Oxford, Clarendon Press, 1973, pp. 204-06.

13.- Estos síntomas clásicos de la enfermedad de amor son descritos en similares términos por Plutarco al narrar la anécdota de la curación de Antíoco como «los famosos síntomas que describe Safo", Vida de Demetrios, en Plutarch, Vies, eds. Robert Flacelière, Emile Chambry y Marcel Juneaux, vol. 13, París: Les Belles-Lettres, 1964, lib. 37, c. 4, p. 60. La importancia del tema de la aegritudo amoris en La Celestina ha sido muy estudiada. Un buen resumen y nuevas interpretaciones están en la reciente obra anteriormente citada de Amasuno, Sobre la aegritudo amoris y otras cuestiones fisiátricas en La Celestina.

14.- Las descripciones clásicas del episodio del diagnóstico que Erasístrato hizo del mal de amor de Antíoco lo presentan tomando el pulso de éste sea en la muñeca, sea apoyando su mano en el corazón. Detallados análisis de este episodio y su transmisión son Bienvenido Morros Mestre, "La difusión de un diagnóstico de amor», Boletin de la Real Academia Española, 79.276 (1999), pp. 93-150; Ruth Lee Kennedy, «The Theme of 'Stratonice' in the Drama of the Spanish Peninsula», PMLA, 55.4 (1945), pp. 1010-32. Para las artes plásticas, véase Wolfgang Stechow, "The Love of Antiochus with Faire Stratonica' in Art», The Art Bulletin, 27.4 (1945), pp. 221-37. 
llorar al que dolor tiene: que las lágrimas e suspiros mucho desenconan el corazón dolorido» (31, énfasis mío). ${ }^{15}$ Este "corazón dolorido» del que habla Sempronio es una traducción al lenguaje lego de la expresión "pletórico corazón» del pedante Calisto. Más adelante, Sempronio confirma que también ha entendido las implicaciones médicas de hinchazón y presión de la plétora de la que se queja Calisto cuando dice para sí: «que he oído decir que es peligro abrir o apremiar las postemas duras». Las apostemas son una inflamación por infección que aparece relacionada con la plétora en los tratados médicos. ${ }^{16}$ Finalmente, en la misma escena, Sempronio vuelve a insistir en la idea del corazón repleto o pletórico de su amo al decir: "Como Melibea es grande, no cabe en el corazón de mi amo, que por la boca le sale a borbollones» (34).

Erasístrato y sus teorías son muy importantes en la historia de la medicina antigua. Aunque no ha sobrevivido ni uno solo de los nueve libros que presuntamente escribió, el corpus galénico y otros textos médicos clásicos abundan en referencias a su nombre y a sus teorías, a menudo acompañándolas de largas citas sacadas de esos libros perdidos. Galeno es, con mucho, quien más lo cita. Aunque Erasístrato había muerto dos siglos antes, Galeno lo menciona en muchos capítulos de su extensa obra como a un oponente cuyas teorías tiene que rebatir. En varias ocasiones incluye largas citas literales sacadas de los textos de Erasístrato para rebatirlas punto por punto, a menudo de manera sarcástica. Esta hostilidad de Galeno hacia la figura de Erasístrato se explica porque, en

15.- Esta cita y todas las siguientes son por número de página a Fernando de Rojas y "Antiguo Autor», La Celestina, tragicomedia de Calisto y Melibea, ed. Guillermo Serés, Francisco J. Lobera, Paloma Díaz-Mas, Carlos Mota, Iñigo Ruiz Arzálluz y Francisco Rico, Barcelona, Crítica, 2000.

16.- La posibilidad de un apostema en el corazón es señalado por Gordonio en el capítulo "Del tremor del coraçón»: «E si viniere apostema al coraçón, o es grande o pequeña etc.». Bernardo de Gordonio, Lilio de medicina: un manual básico de medicina medieval, ed. John Cull y Brian Dutton, Madison, Hispanic Seminary of Medieval Studies, 1991, p. 203. En Celestina comentada, p. 13, el anónimo comentarista cita varias de las fuentes médicas: «Esto es porque no ai cosa mas mala para las enfermedades que la medicina hecha con tiempo o sazon como seria esta abrir las apostemas quando no estan sazonadas. [^Y ansi lo dize Seneca cap. 1 en el libro De consolatione ad Helviam: "In morbis quoque nihil est magis periculosum, nec perniciosum quam immatura medicina». Y es de Hyppocras en muchas partes en especial en el 4 De victus ratione in morbis acutis en el texto que dize ansi: "Qui statim inter initia morbi inflammationes medicina solvere conantur intensa inflammata parte nihil auferunt [ilegible] vero ut pote [ilegible] non remittitur de parte sana et morbo resistent (^ilegible) colliquescunt etc». ('Qualquiera que en el principio de la enfermedad procura sanar de qualquiera manera las apostemas estorba alguna cosa sana de la parte apostemada [ilegible] y la [ilegible] esta crudo el humor no se quita ni [ilegible] y

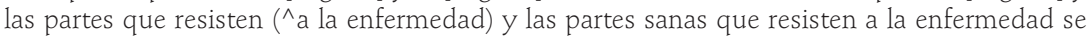
deshazen'). Y en el libro De humoribus: "Matura medicaminibus purgato, non cruda» ('Purgaros con medicinas y lo mismo con cauterio el humor maduro no lo crudo'). Y en el 2 de las Amphorismos en el tx. 22: "Concocta medicamentis purgato non cruda». Esto tanbien quiere Avicena en la 1, 4 tract. 2 cap. 7 y en otras muchas partes. Y ansi queda bien averiguado ser estas palabras proposicion de medicos]». 
la Roma en que Galeno practicaba la medicina, los discípulos de Erasístrato formaban una poderosa escuela que usaba métodos terapéuticos muy diferentes a los suyos. ${ }^{17}$ En sus ataques, Galeno se muestra especialmente hostil con la teoría de la circulación de Erasístrato, la cual proponía que el sistema vascular no sólo distribuía la sangre sino también lo que Erasístrato denominaba pneuma, un concepto complejo que aparece traducido como spiritus en latín y que parece incluir el aire junto con un principio vital como el espíritu animal o ánima. ${ }^{18}$ Según esta teoría, el ventrículo izquierdo distribuía exclusivamente el pneuma, mientras que el derecho se encargaba de la sangre. Igualmente, mientras que las arterias llevaban el pneuma, las venas llevaban sólo sangre. Únicamente al alcanzar los órganos había cierta comunicación entre ambos sistemas por una especie de osmosis. La plétora era consecuencia de un fallo en este proceso y resultaba en un desequilibrio por el exceso de sangre retenida y la resultante falta de pneuma en el órgano. Estas teorías se enfrentaban directamente con las de Galeno y la escuela hipocrática, que sostenían que el sistema circulatorio llevaba exclusivamente sangre y no pneuma. Este desacuerdo entre ambas escuelas, que hoy puede parecer un mero tecnicismo, era muy importante en la época ya que suponía una concepción diferente del funcionamiento del cuerpo humano y, por tanto, de los métodos para curarlo. ${ }^{19}$

La hostilidad de Galeno con Erasístrato y sus teorías se muestra en muchos de sus libros pero alcanza especial virulencia en el que lleva el significativo título De venae sectione adversus Erasistratum (Contra Erasistrato sobre la flebotomía). Como bien es sabido, Galeno era un gran defensor de las sangrías y es el responsable de su extendido uso hasta tiempos relativamente recientes. Por ello, en este libro no sólo ataca sino que también se burla de la oposición de Erasístrato y sus seguidores a la práctica de las sangrías. Según cuenta Galeno, Erasístrato sostenía que se producía un escape del pneuma al cortar una arteria. Dado que el pneuma o spiritus es un elemento sutil, esta pérdida era instantánea e imperceptible. El espacio que el pneuma dejaba vacío al escaparse era ocupado inmedia-

17.- Además de los resúmenes de su vida en los manuales de historia de la medicina y otras obras enciclopédicas, existen varios estudios detallados sobre la figura de Erasístrato. Véase J.F. Dobson, «Erasistratus», Proceedings of the Royal Society of Medicine, 20 (1926-1927), pp. 825-32; Iain Lonie, «Erasistratus, the Erasistrateans, and Aristotle», Bulletin of the History of Medicine, 38 (1964), pp. 426-43; P.M. Fraser, "The Career of Erasistratos», Rendiconti dell Instituto Lombardo, 103 (1969), pp. 518-37.

18.- Así como ocurre en otros autores de la antigüedad, la relación exacta entre el pneuma y el alma no está clara en Erasístrato. En ocasiones, el pneuma es presentado como un mero vehículo del alma, en otras, como el alma misma. Esta confusión se ve complicada por la clásica división del ánima en tres (vegetativa, sensitiva, racional) o más tipos. Véase Boyd Hill, "The Grain and the Spirit in Mediaeval Anatomy», Speculum, 40.1 (1965), pp. 63-73.

19.- Véase esta disputa en detalle en Leonard Wilson, «Erasistratus, Galen, and the Pneuma», Bulletin of the History of Medicine, 33 (1959), pp. 294-314. 
tamente por la sangre que acudía atraída por el horror vacui, de ahí que fluyera sangre del corte de manea casi inmediata (XI,153-54; IV, 714). ${ }^{20} \mathrm{Ga}$ leno ridiculiza esta teoría mencionando varias contradicciones internas y pruebas de experimentos que él realizó. En este libro y otros, Galeno se burla del sistema de curar las plétoras o inflamaciones utilizada por los seguidores de Erasístrato, quienes, en vez de practicar las sangrías, se limitaban a recomendar una serie de medidas terapéuticas suaves, como dietas blandas, baños, masajes y ejercicio. ${ }^{21}$ No sólo Galeno sino también otros médicos de la antigüedad se muestran hostiles con las teorías de la circulación sanguínea de Erasístrato y sus medidas terapéuticas. Así, en el proemio de su De medicina, Celso descalifica la teoría de Erasístrato de que la fiebre sea producto de la plétora resultante del trasvase de sangre al sistema arterial. ${ }^{22}$ Otros médicos de la antigüedad tardía, probablemente influenciados por Galeno, incluyen en sus textos ataques similares contra Erasístrato. Celio Aureliano, en su libro Acutae passiones, en el capítulo sobre la passio cardiaca, cita extensamente para contradecirla la teoría de Erasístrato de que esta enfermedad era un caso de inflamación en la zona del corazón. Igualmente, en su libro Chronicae passiones habla en términos despectivos de la teoría de Erasístrato de que el corazón puede sufrir apostemas, así como de su recomendación de no hacer sangrías. ${ }^{23}$

Galeno es el que va más lejos en sus ataques contra Erasístrato, no sólo por la frecuencia y virulencia de éstos, sino también porque a menudo en sus escritos hace de Erasístrato un interlocutor con el que habla en segunda persona, como si estuviera vivo y presente, lanzándole desafíos a que se defienda de los argumentos que avanza contra sus teorías. Podemos citar como ejemplo un pasaje del Adversus Erasistratum de venae sectione en el que Galeno cita un extenso texto de Erasístrato donde éste diagnóstica un caso de plétora. Al terminar la cita, Galeno se dirige en segunda persona a Erasístrato, como si estuviera vivo, con la exclamación y el vocativo,

20.- Cito la versión latina de Galeno por número de volumen y página de la edición de Kühn antes citada.

21.- Galeno se burla de los seguidores de Erasístrato por sus reparos a practicar sangrías

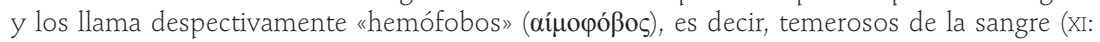
302). Para el caso de palpitaciones súbitas que sin otro síntoma o causa aparente aparecen tanto en jóvenes como en adultos recomienda Galeno la sangría (viII: 305). Un resumen de la práctica de la sangría en Galeno es Brain, Galen on Bloodletting: A Study of the Origins, Development, and Validity of his Opinions, with a Translation of the Three Works, Cambridge, Cambridge University Press, 1986, pp. 122-34. Sobre la importancia de las sangrías en la época, véase Pedro Gil-Sotres, «Sangre y patología en la medicina bajomedieval: el substrato material de la flebotomía", Misterio y realidad: estudios sobre la enfermedad humana, ed. Agustín Albarracín, Madrid, Centro de Estudios Históricos, 1988, pp. 73-103.

22.- Aulus Cornelius Celsus, De medicina, ed. W.G. Spencer, Cambridge, Mass., Harvard University Press, 1935, p. 32.

23.- Caelius Aurelianus, On Acute Diseases and On Chronic Diseases, ed. I.E. Drabkin, Chicago, University of Chicago Press, 1950, pp. 163, 175, 690, 974. 
"O Erasistrate», y pasa a refutar el diagnóstico (xIx: 209). Igualmente, en el libro De naturalibus facultatibus, Galeno interpela irónicamente a Erasístrato en varias ocasiones. En un pasaje que habla del estómago, Galeno escribe: «¿De qué estás tratando de manera tan retórica y sin pruebas, oh nobilísimo [Erasístrato]» ("Quid ita nos rhetorice sine demostratione, o nobilissime, transcurris?) (II: 61), y más adelante continua: «[L]e rogaría al mismísimo Erasístrato que me lo explicara» («rogarem mihi responderet ipse Erasistratus») (II: 83).

Un caso especialmente curioso del antagonismo que Galeno muestra con Erasístrato se puede ver en su libro De praenotione ad Posthumum. Allí Galeno descalifica el famoso diagnóstico de Erasístrato de la enfermedad de Antíoco - al que Galeno sólo identifica como un joven enamorado de una esclava de su padre. Tras narrar brevemente la anécdota, Galeno añade que no está seguro de cómo Erasístrato realizó este diagnóstico, pero que, en su opinión, fue un mero acierto fortuito. Pasa Galeno a describir un caso similar en que él mismo dictaminó que una matrona romana sufría de un mal semejante por amor de un bailarín llamado Pilades, la mera mención de cuyo nombre hacía saltar el corazón de la dama. Sin embargo, Galeno concluye la anécdota matizando: «Decir que el pulso se excita por temas de amor es una tontería que dicen los que ignoran que el pulso no es indicador de que alguien esté enamorado, sino que el pulso se altera al ser el ánima turbada por cualquier cosa, y no conserva ni su ritmo ni orden natural» («Nugae igitur sunt pulsus amatorie moti eorum qui ignorant nullum pulsum amatoris esse indicem, sed anima turbata ob quamcumque rem pulsus alterari, neque naturalem aequalatitem neque ordinem conservantes») (XIV: 635, traducción mía). ${ }^{24}$ Esta imagen negativa de Erasístrato de la que Galeno es el principal responsable aparece tipificada en una obra falsamente atribuida a Luciano de Samosata pero que en realidad es una sátira bizantina del siglo XII, el Timarión, que contiene un descenso burlesco al infierno de su protagonista homónimo. Aunque esta obra no circuló en occidente, es un buen resumen de la imagen negativa de Erasístrato y de la descalificación de su famoso diagnóstico. Durante su vistita al infierno, Timarión se encuentra con un sofista que expresa su opinión de los médicos famosos de la antigüedad. Todos salen malparados, excepto Galeno, y sólo en parte. Especialmente malparado sale Erasístrato, del que el sofista dice que no conoce las reglas de cómo argumentar, y que ni siquiera es un teórico competente, pero que consiguió su inmerecida fama gracias a su sagacidad y a algunos casos que for-

24.- Este diagnóstico de Galeno puede ser una anécdota verdadera o una invención suya pues en otro de sus escritos narra una anécdota muy similar en la que el enfermo es un varón. Sobre esta posibilidad véase Susan P. Mattern, Galen and the Rhetoric of Healing, Baltimore, The John Hopkins UP, 2008, p. 217, nota 128. 
tuitamente curó, especialmente el de Antíoco. ${ }^{25}$ Volviendo al texto de La Celestina, al referirse a su "pletórico corazón» Calisto sigue con la misma línea iniciada en su invocación de Erasístrato al principio del pasaje. La invocación inicial a Erasístrato ("O si viniessedes agora etc.») no se limita a servir de introducción a la famosa anécdota de su cura de Antíoco sino que imita la tradición galénica de hacer de un Erasístrato redivivo un interlocutor al que apostrofar en tono sarcástico. La contigua referencia de Calisto a su corazón enfermo como "pletórico corazón» utiliza también la tradición galénica de burlarse de Erasístrato y su escuela al mencionar su más controvertida teoría: la plétora y la circulación separada de sangre y pneuma. Calisto está pues combinando en este pasaje las dos tradiciones por las que la figura de Erasístrato era famosa: la reflejada en la anécdota de tradición literaria del diagnóstico que hiciera del amor de Antíoco, y la plasmada en el corpus galénico y en otros textos médicos clásicos que se burlan de sus teorías. Calisto no es totalmente novedoso en mezclar estas dos imágenes ya que, como vimos, el mismo Galeno lo hace en su De praenotione ad Posthumum, donde cita la anécdota de este diagnóstico que Erasístrato hiciera del mal de amor para luego descalificarla como un mero caso fortuito. No hay que olvidar que la familiaridad con los textos galénicos era frecuente no sólo entre los que habían estudiado medicina sino también entre aquellos que tenían una formación humanista en general. Sin embargo, a medida que el corpus galénico dejó de ser leído con la gradual implantación de la medicina empírica desde el Renacimiento, la imagen negativa de Erasístrato se fue perdiendo. Por el contrario, la imagen positiva de su portentosa cura de Antíoco se ha mantenido hasta nuestros días gracias a la fortuna literaria de la bella historia de amor contenida en la anécdota. ${ }^{26}$

Esta invocación sarcástica de la figura de Erasístrato al modo de los textos galénicos es utilizada por Calisto para alardear de un mal de amor aun más grave que el del legendario caso de Antíoco. Calisto está diciendo que, aunque Erasístrato no tendría ninguna dificultad en diagnosticar su afección por las palpitaciones de su corazón, su gravedad es tal que sería incapaz de curarlo. Esta incapacidad de Erasístrato para curarlo está contenida in nuce en el irónico autodiagnóstico que Calisto adelanta de su mal de amor. Al referirse a su "pletórico corazón» está trayendo a colación la dudosa reputación médica de Erasístrato que ya había adelantado en el desafiante tono con que lo interpela al principio del pasaje al modo

25.- Barry Baldwin, tr. y ed., Timarion, Detroit, Wayne State University Press, 1984, p. 61. Curiosamente la reputación de Erasístrato como médico es hoy positiva, ya que se anticipó en muchas de sus teorías a lo que la medicina moderna ha descubierto. Como un ejemplo de sus contribuciones y lo acertado de algunas de sus teorías, véase el artículo ya citado de Dobson, «Erasistratus».

26.- Para la fortuna en la literatura y en las artes plásticas de la historia de Antíoco y Estratonice, véase la nota 14. 
de los textos galénicos. En estos mismos textos, las plétoras que Erasístrato diagnostica indiscriminadamente y las curas blandas que recomienda son el principal argumento para presentarlo como un dogmático que quiere reducir cualquier dolencia a un desorden explicable mediante su indefendible teoría de la circulación separada de la sangre y el pneuma.

Es en esta misma línea descalificadora de la figura de Erasístrato en la que hay que entender la referencia de Calisto a la "piedad de Seleuco". Esta no está usada aquí en sentido literal de un padre que renuncia a su esposa por el bien de su hijo, sino en el sentido genérico de cura, más específicamente del tipo de cura «blanda» típica de Erasístrato, tan diferente de las sangrías preconizadas por Galeno. ${ }^{27}$ Que Calisto usa "piedad de Seleuco» no para aludir a que el padre de Melibea realice algún tipo de acción o renuncia en su favor se colige de la falta de semejanzas entre el caso de Calisto y el de Antíoco. Excepto la enfermedad de amor, en nada se parecen ambos casos, pues ni Melibea es su madrastra, ni está casada con su padre, ni es concebible que Melibea se presente en su habitación y le produzca una alteración del pulso, amén de otras diferencias. Esta misma laxitud de Calisto a la hora de establecer comparaciones con casos famosos de mal de amor de la antigüedad que pretende superar se repite unas líneas más abajo en la misma escena. Cuando Sempronio intenta aliviarlo distrayéndolo con la interpretación del famoso romance "Mira Nero de Tarpeya la Roma cómo se ardía», Calisto le interrumpe diciéndole que mayor que aquel fuego es el que le quema a él. Sempronio pone de relieve la inapropiada comparación al cuestionar que cómo es posible comparar el fuego que quemó a toda una ciudad con el que atormenta a un solo ser humano (33).

La figura de Erasístrato —en particular sus teorías sobre la circulación del pneuma y su consecuente oposición a la sangría - está también presente en la amenaza de suicidio implícita en el final del pasaje: "porque sin esperanza de salud no embie el espiritu perdido con el desastrado Piramo y de la desdichada Tisbe». Que Calisto amenaza con suicidarse se ve claramente en el miedo que unas líneas más adelante Sempronio muestra a que su amo se quite la vida si lo deja solo ("pero si se mata sin otro testigo yo quedo obligado a dar quenta de su vida») (30). ${ }^{28} \mathrm{Al}$ igual que cuando estableciera la comparación de su caso con el de Antíoco,

27.- La sangría era la terapia predominante para tratar muchas enfermedades, incluida la melancolía erótica, y así se recomendaba todavía sangrar la vena media o cardiaca en el tratado de 1628 de Jacques Ferrand, A Treatise on Lovesickness, eds. Donald Beecher y Massimo Ciavolella, Syracuse, Syracuse University Press, 1990, p. 356.

28.- Aunque en cierto momento Sempronio considera que puede beneficiarle la muerte de su amo ("si entretanto se matare, muera. Quizá con algo me quedaré que otro no lo sabe» [31]), según la ley de la época su responsabilidad sería mucha en tal caso: "Question es de derecho que si uno se halla muerto en una casa sin saber quien lo mato si se presume ser muerto de aquellos que estavan con el en la casa. Tratalo Romano en el consejo 401. Angelo 'De maleficiis' in pte. fama publica verb. quid autem si sunt quinque. Y es lei de romance que ansi lo 
Calisto se compara con Píramo no porque haya un especial parecido entre la historia de Píramo y Tisbe con la suya con Melibea, la cual ni está enamorada de él, ni ha acordado una cita, ni, en ese momento inicial de la relación, se suicidaría si descubriera que Calisto ha muerto. A pesar de la falta de parecido en las situaciones, Calisto establece esta comparación con Píramo y Tisbe por ser esta pareja la epónima del suicidio por amor. En concreto, dado el contexto médico del pasaje, la comparación enfatiza el método de suicidio de darse una puñalada en el corazón que aquellos amantes utilizaron. En el contexto de las teorías circulatorias y terapéuticas de Erasístrato implícitas en el pasaje, la amenaza del histriónico Calisto de apuñalarse resuena a una sangría suicida. Calisto presume que ésta es la única solución posible para su dolencia, una dolencia tan grave que ni el legendario Erasístrato sería capaz de curar recurriendo al azar, la agudeza y la terapia blanda de interceder ante Seleuco que tan bien le funcionó en el caso de Antíoco. ${ }^{29}$

En esta amenaza de suicidio de Calisto también resuenan las teorías de Erasístrato del pneuma y su circulación en la aliteración etimológica presente en las palabras «inspira» y "espíritu». Estas dos palabras que la aliteración pone de relieve apuntan al pneuma en la forma latina «spiritus» usada en los textos galénicos. Así, la secuencia "porque sin esperança de salud no embie el espiritu perdido» va más allá de ser el manido eufemismo de morir como rendir el alma para convertirse en una descripción sarcástica del suicidio en términos de las teorías circulatorias de Erasístrato, según las cuales el efecto de una puñalada en el corazón sería una fuga letal del pneuma del ventrículo izquierdo. La palabra «inspire» contribuye a este sentido ya que cobra en este pasaje el sentido literal de insuflar o soplar aire o líquido que es frecuente en los textos médicos. Un ejemplo de este uso se puede ver en los Diálogos familiares de la agricultura cristiana (1589), de Juan de Pineda, quien, al citar las ideas de Hipócrates sobre el corazón, habla de «los fuelles para recibir el aire refrigerativo del si-

dize que el morador de la casa sea tenido de mostrar quien lo mato es 1.3 tto 17 lib. 4 Fori» (Celestina comentada, p. 12).

29.- Según Ovidio - la fuente más famosa y prácticamente la única que cuenta de manera detallada esta famosa historia-, Píramo se clavó un cuchillo en el corazón y el resultado fue «no de otro modo que cuando se abre una fisura en una cañería y por el pequeño agujero sale un poderoso chorro de agua que sube en el aire a borbotones ("non aliter quem cum vitiato fistula plumbo / scinditur et tenui stridente foramine longas ejaculatur aquas / atque ictibus aera rumpitur») (Metamorphosis IV: 122-24, traducción mía). Esta referencia a la cañería y al exceso de presión le sirve a Ovidio para indicar la intensidad del amor que había en el corazón de Píramo. En el contexto médico que tienen las palabras de Calisto, la imagen del chorro de sangre de Píramo apuntaría también a la presión de la plétora. Esta supuesta salida atropellada de la sangre de Calisto si se apuñalara el corazón parece tener un eco jocoso en las palabras de Sempronio cuando se burla de su amo diciendo: "Como Melibea es grande, no cabe en el corazón de mi amo, que por la boca le sale a borbollones» (34, énfasis mío). 
niestro ventrículo, que inspira en el diestro». ${ }^{30}$ En otras palabras, Calisto conmina a Erasístrato a que pruebe a curarlo con sus simplistas terapias de restablecer el equilibrio del pneuma insuflando su cura - la piedad de Seleuco- como si se tratara de una infusión de pneuma en el órgano afectado. Si no, amenaza, se suicidará, una acción que presenta también en la terminología de la circulación del pneuma o espíritu como una letal sangría de su corazón.

Para concluir, quiero recalcar que esta enmienda textual de "pletórico corazón» por "plebérico corazón" afecta a la protohistoria textual de $\mathrm{La}$ Celestina, es decir, a la versión del Antiguo Autor. Rojas, sea porque ya estaba corrupto el pasaje en la copia que le llegó o porque él mismo leyó mal el pasaje, no transcribió "pletórico", sino "plebérico", y a partir de ahí creó el personaje de Pleberio y el resto de La Celestina que conocemos hoy. Sin embargo, esta corrección cumple dos objetivos. Por un lado sirve para confirmar la validez de las correcciones de «Erasístrato» y "piedad de Seleuco». Por otro, permite entender mejor este complejo pasaje al revelar las diferentes capas de que está constituido. Con esta nueva interpretación, su significado no se desvía de la imagen de un Calisto que, para encarecer la gravedad su mal de amor — "Cual dolor puede ser tal / que se iguale con mi mal», que presuntuosamente canta en la misma escena (32)-, se compara, para superarlo, con el legendario caso de Antíoco. La alusión a Erasístrato se convierte ahora en la clave de todo el pasaje, con una función mayor que la que hasta ahora se le atribuía. Calisto está alardeando de la gravedad de su mal echando mano simultáneamente de las dos tradiciones de Erasístrato, la de los textos galénicos y la literaria. Comienza utilizando la práctica de apostrofar a Erasístrato de los textos galénicos para introducir la imagen literaria del Erasístrato como el sanador del enamorado Antíoco. Inmediatamente y en la misma tradición galénica con la que ha empezado, Calisto introduce la imagen negativa de Erasístrato de un médico dogmático que diagnostica todas las enfermedades como casos de plétora, y de un charlatán que logró curar a Antíoco más por puro azar que por sus conocimientos. Pero, esta vez, a Erasístrato redivivo no le servirían de nada esas artimañas porque su mal de amor por Melibea, presume Calisto, es mucho más grave que el legendario de Antíoco por Estratonice.

30.- Juan de Pineda, Diálogos familiares de la agricultura cristiana, vol. 162, Madrid, BAE, 1963, p. 235, énfasis mío. Un uso semejante de un juego de palabras basado en el significado técnico y el común de una palabra se produce unas líneas más abajo en este mismo diálogo entre Calisto y Sempronio, cuando al empezar a tocar su amo el laúd, dice éste: «Destemplado está ese laúd», a lo que Calisto responde: “¿Cómo templará el destemplado? ¿Cómo sentirá el armonía aquel que consigo está tan discorde?», palabras donde hay un juego basado en el sentido técnico de "templar» como afinar un instrumento para alcanzar armonía y su sentido general aplicable en este contexto de remediar la alteración que invade a Calisto (Rojas, p. 32 y nota 76). 


\section{Bibliografía citada}

Amasuno, Marcelino V. Sobre la aegritudo amoris y otras cuestiones fisiátricas en La Celestina. Madrid: CSIC, 2005.

Aurelianus, Caelius. On Acute Diseases and On Chronic Diseases. Ed. I.E. Drabkin. Chicago: University of Chicago Press, 1950.

Baldwin, Barry, tr. y ed. Timarion. Detroit: Wayne State University Press, 1984.

BARTH, Kaspar von. Pornoboscodidascalus Latinus (1624), Kaspar Barth's NeoLatin Translation of Celestina. Ed. Enrique Fernández. Chapel Hill: North Carolina Studies in the Romance Languages and Literatures, 2006.

BotтA, Patrizia. "Onomástica y crítica textual: peripecias de los nombres propios en La Celestina». Criticón, 87-88-89 (2003), pp. 97-111.

Brain, Peter. Galen on Bloodletting: A Study of the Origins, Development, and Validity of his Opinions, with a Translation of the Three Works. Cambridge: Cambridge University Press, 1986.

Cañizo y García, Agustín del. Las cardiopatías de la plétora. Madrid: Sucesor de Enrique de Teodoro, 1917.

Castells, Ricardo. "El mal de amores de Calisto y el diagnóstico de Eras y Crato, médicos». Hispania, 76.1 (1993), pp. 55-60.

Cejador y Frauca, J., ed. La Celestina. 2 vols. Madrid: Espasa Calpe (1913), 1968.

Celestina comentada. Ed. Louise Fothergill-Payne, Enrique Fernández Rivera y Peter Fothergill-Payne. Salamanca: Ediciones Universidad de Salamanca, 2002.

Celsus, Aulus Cornelius. De medicina. Ed. W.G. Spencer. Cambridge, Mass.: Harvard University Press, 1935.

Dobson, J.F. "Erasistratus». Proceedings of the Royal Society of Medicine, 20 (1926-1927), pp. 825-32.

Ferrand, Jacques. A Treatise on Lovesickness. Eds. Donald Beecher y Massimo Ciavolella. Syracuse: Syracuse University Press, 1990.

FRASER, P.M. "The Career of Erasistratos». Rendiconti dell Instituto Lombardo, 103 (1969), pp. 518-37.

Fuchs, R. «Die Plethora bei Erasistratos». Neue Jahrbüche für Philologie und Pädagogie 38 (1892), pp. 679-91.

Galeno. Claudii Galeni opera omnia. Medicorum Graecorum opera quae extant. Ed. Karl Gottlob Kühn. 20 vols. Hildeshei:, Olms (Reprographischer Nachdruck der Ausg. Leipzig, 1821-33), 1964.

Gil-Sotres, Pedro. "Sangre y patología en la medicina bajomedieval: el substrato material de la flebotomía». Misterio y realidad: estudios sobre la enfermedad humana. Ed. Agustín Albarracín. Madrid: Centro de Estudios Históricos, 1988, pp. 73-103. 
Gordonio, Bernardo de. Lilio de medicina: un manual básico de medicina medieval. Sevilla, 1495. Ed. John Cull y Brian Dutton. Madison: Hispanic Seminary of Medieval Studies, 1991.

Harris, Charles R. S. The Heart and the Vascular System in Ancient Greek Medicine from Alcmaeon to Galen. Oxford: Clarendon Press, 1973.

Herrera, María Teresa. Diccionario español de textos médicos antiguos. 2 vols. Madrid: Arco Libros, 1996.

HILl, Boyd H. "The Grain and the Spirit in Mediaeval Anatomy». Speculum, 40.1 (1965), pp. 63-73.

Kennedy, Ruth Lee. "The Theme of 'Stratonice' in the Drama of the Spanish Peninsula». PMLA, 55.4 (1945), pp. 1010-32.

LonIE, Iain. "Erasistratus, the Erasistrateans, and Aristotle». Bulletin of the History of Medicine 38 (1964), pp. 426-43.

Marciales, Miguel, ed. Celestina: Tragicomedia de Calisto y Melibea. Illinois Medieval Monographs. Edición al cuidado de Brian Dutton y Joseph T. Snow. 2 vols. Urbana: University of Illinois Press, 1985.

MatTern, Susan P. Galen and the Rhetoric of Healing. Baltimore: The John Hopkins UP, 2008.

McGrady, Donald. "Two Studies on the Text of the Celestina». Romance Philology, 48.1 (1994), pp. 1-21.

Morros Mestre, Bienvenido. "La Celestina como Remedium Amoris». Hispanic Review, 72 (2004), pp. 77-99.

-. "La difusión de un diagnóstico de amor». Boletín de la Real Academia Española, 79.276 (1999), pp. 93-150.

Pineda, Juan de. Diálogos familiares de la agricultura cristiana. Vol. 162. Madrid: BAE, 1963.

Plutarch. Vida de Demetrios. En Vies. Eds. Robert Flacelière, Emile Chambry y Marcel Juneaux. Vol. 13. París: Les Belles-Lettres, 1964.

RojAs, Fernando de. La Celestina: Two Facsimiles (1499? and 1528). New York: Hispanic Society of America, 1995.

-, y "Antiguo Autor». La Celestina, tragicomedia de Calisto y Melibea. Ed. Guillermo Serés, Francisco J. Lobera, Paloma Díaz-Mas, Carlos Mota, Iñigo Ruiz Arzálluz y Francisco Rico. Barcelona: Crítica, 2000.

Ruiz Ramón, Francisco. "Nota sobre la autoría del Acto i de La Celestina». Hispanic Review, 42 (1974), pp. 431-35.

Seniff, Dennis. «Bernardo Gordonio's Lilio de medicina: A Possible Source of Celestina». Celestinesca, 10.1 (1986), pp. 13-18.

SteCHow, Wolfgang. "The Love of Antiochus with Faire Stratonica' in Art». The Art Bulletin, 27.4 (1945), pp. 221-37.

Wilson, Leonard. "Erasistratus, Galen, and the Pneuma». Bulletin of the History of Medicine, 33 (1959), pp. 294-314. 


\section{FernánDez Rivera, Enrique, «El plebérico corazón, Erasístrato y la plétora», Celestinesca, 33 (2009), pp. 71-85.}

\section{RESUMEN}

Defiendo que «plebérico corazón» es una lectura errónea de Rojas u otro copista del original del Antiguo Autor, en el que se leía «plethórico corazón». Además de razones paleográficas, me baso en que, junto con su cura de Antíoco, Erasístrato era famoso por aparecer ridiculizado en los textos galénicos por su atribución de casi todas las enfermedades a la plétora o abundancia de fluidos, para la que recomienda curas que excluían las sangrías. Con "pletórico corazón» Calisto se refiere a su propio corazón enfermo de amor. Para encarecer su inigualable dolor, Calisto reta a Erasístrato a intentar sanarlo con sus métodos curativos, como hiciera con Antíoco. Calisto opone a los métodos no cruentos de Erasístrato una sangría suicida en su corazón similar a la puñalada que Píramo se asestara en el pecho.

PALABRAS ClAVE: La Celestina, Erasístrato, plétora.

\section{ABSTRACT}

I propose that Rojas or another copyist misread "plethórico corazón» as «plebérico corazón" in the manuscript by Celestina's first author. As well as being based on palaeographic arguments, this proposal relies on Erasistratus' famous diagnostic of Antiochus and on his notoriety for being derided in many Galenic texts for his belief that the plethora - superabundance of fluids - was the cause of most diseases, and for recommending cures that excluded bloodletting. Calisto's words "plethórico corazón" refer to his own enamoured heart. Boasting of his unmatchable pain, he challenges Erasistratus to cure him with the same remedies he had applied to Antiochus successfully. Mockingly, Calisto threatens to perform a suicidal bloodletting procedure by stabbing his heart as the legendary Pyramus did.

KEY WORDS: Celestina, Erasistratus, plethora.

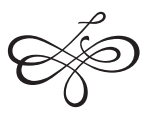

